\title{
A Cibernética do "Self": uma Teoria do Alcoolismo $(1971)^{1}$
}

\section{Gregory Bateson ${ }^{1}$}

${ }^{1}$ Antropólogo britânico, pioneiro do movimento da cibernética. Foi professor e pesquisador em múltiplos institutos de pesquisa e universidades no Reino Unido e Estados Unidos

\section{Tradução: Letícia Maria Costa da N. Cesarino²}

${ }^{2}$ Universidade Federal de Santa Catarina, Florianópolis, Brasil 


\section{Resumo}

Neste texto clássico, originalmente publicado em 1971, Gregory Bateson propõe uma "explicação cibernética" para a eficácia da metodologia de Alcoólicos Anônimos (AA). Ao fazê-lo, oferece uma teoria complexa e original para a formação do "self" na cultura ocidental.

Palavras-chave: Alcoólicos Anônimos. Cibernética. Alcoolismo.

\section{Abstract}

In this popular text originally published in the 1971, Gregory Bateson puts forth a "cybernetic explanation" for the efficacy of Alcoholics Anonymous' methodology. Along the way, it offers a complex and original theory for the formation of the "self" in Western culture.

Keywords: Alcoholics Anonymous. Cybernetics. Alcoholism. 


\section{Introdução}

"lógica" da adição alcoólica tem intrigado os psiquiatras, mas
não mais que a "lógica" do regime espiritual rígido por meio do qual a organização Alcoólicos Anônimos - doravante, AA - tem se mostrado capaz de combatê-la. No presente ensaio sugiro que: (i) uma epistemologia inteiramente nova deve emergir a partir da cibernética e da teoria de sistemas, envolvendo uma nova compreensão da mente, do self, das relações humanas e do poder; (ii) quando sóbrio, o alcoólatra adicto opera nos termos de uma epistemologia que é convencional na cultura ocidental, mas que não é aceitável para a teoria de sistemas; (iii) "render-se" à intoxicação alcoólica é um atalho parcial e subjetivo para um estado mental mais correto; e (iv) a teologia de Alcoólicos Anônimos se aproxima da epistemologia da cibernética.

O presente ensaio se baseia em ideias que são familiares tanto para os psiquiatras, que têm lidado com alcoólatras, quanto para os filósofos, que têm refletido sobre as implicações da cibernética e da teoria de sistemas. A única novidade possível de ser reivindicada para as teses aqui avançadas está na seriedade com que trato essas ideias como premissas argumentativas e na aproximação entre ideias comuns vindas de dois campos de pensamento que têm se desenvolvido em paralelo.

Este ensaio foi originalmente pensado como um estudo teóricosistêmico da adição alcoólica baseado em dados das publicações de Alcoólicos Anônimos, organização que tem o único histórico notável de sucesso no trabalho com alcoólatras. Logo ficou claro, porém, que a visão religiosa e a estrutura organizativa de AA apresentam pontos de grande interesse para a teoria de sistemas, e que o escopo correto 
de meu estudo deveria incluir não apenas as premissas do alcoolismo, mas também as premissas do sistema desenvolvido por AA para tratálo, bem como da própria organização de AA.

Minha dívida com AA ficará evidente aqui - assim como, espero, meu respeito por esta organização, e especialmente pela extraordinária sabedoria de seus cofundadores, Bill W. e Dr. Bob.

Além disso, devo reconhecer minha dívida para com uma pequena amostra de pacientes alcoólatras com quem trabalhei intensivamente durante cerca de dois anos, entre 1949 e 1952, no Veterans Administration Hospital em Palo Alto, Califórnia. Esses homens, isto deve ser dito, tinham outros diagnósticos - em sua maioria, de "esquizofrenia" associados às dores do alcoolismo. Vários eram membros de Aas, temo não os ter ajudado em nada.

\section{O Problema}

É geralmente aceito que as "causas" ou "razões" do alcoolismo devam ser buscadas na vida sóbria do alcoólatra. Em suas manifestações de sobriedade, os alcoólatras são comumente chamados de "imaturos", "fixados maternal ou oralmente", "homossexuais", "orgulhosos", "afáveis", ou simplesmente "fracos". Mas as implicações dessa crença normalmente não são examinadas:

1) Se a vida sóbria do alcoólatra de alguma forma o impulsiona a beber ou propõe o primeiro passo para a intoxicação, é improvável que qualquer procedimento que reforce seu estilo particular de sobriedade reduza ou controle seu alcoolismo.

2) Se seu estilo de sobriedade o leva a beber, então esse estilo deve conter erro ou patologia, e a intoxicação deve oferecer alguma forma de correção - ainda que subjetiva - desse erro. Em outras palavras, comparada com sua sobriedade, que é de alguma forma "errada", sua intoxicação deve ser de alguma forma "correta". O velho ditado in vino veritas deve conter uma verdade mais profunda do que a que lhe é usualmente atribuída. 
3) Uma hipótese alternativa sugere que, quando sóbrio, o alcoólatra é de alguma forma mais são do que as pessoas à sua volta, e que essa situação se torna intolerável. Eu tenho ouvido alcoólatras argumentarem em favor dessa possibilidade, mas devo ignorá-la neste ensaio. Eu penso que Bernard Smith, representante legal não-alcoólatra de AA, chegou perto deste ponto ao afirmar que "[...] o membro (de AA) nunca foi escravizado pelo álcool. O álcool simplesmente servia como um escape da escravização pessoal aos ideais de uma sociedade materialista" (AA, 1957, p. 279, grifo meu). Não é uma questão de revolta contra os ideais insanos que o cercam, mas de escapar de suas próprias premissas insanas, que são continuamente reforçadas pela sociedade à sua volta. É possível, no entanto, que o alcoólatra seja de alguma forma mais vulnerável ou sensível que a média ao fato de que suas premissas insanas (porém convencionais) levem a resultados insatisfatórios.

4) A presente teoria do alcoolismo oferecerá um ajuste inverso [converse matching] entre sobriedade e intoxicação, de forma que esta última possa ser vista como uma correção subjetiva e apropriada da primeira.

5) Há, é claro, muitas situações nas quais as pessoas recorrem ao álcool e mesmo à intoxicação extrema como um tipo de anestésico para aliviar um sentimento de perda e ressentimento, ou alguma dor física. É possível argumentar que a ação anestésica do álcool ofereça um ajuste reverso suficiente para nossos propósitos teóricos. Devo, no entanto, desconsiderar esses casos particulares por serem irrelevantes para o problema do alcoólatra repetitivo ou adicto; e isso, não obstante do fato inegável de que "luto", "ressentimento" e "frustração" são frequentemente utilizados por alcoólatras adictos como desculpa para beber.

Devo buscar, portanto, um ajuste inverso mais específico entre a sobriedade e a intoxicação do que a simples anestesia. 


\section{Sobriedade}

Os amigos e familiares do alcoólatra normalmente incentivam-no a ser "forte" e "resistir à tentação". Não é muito claro o que querem dizer com isso, mas é significativo que o próprio alcoólatra, quando sóbrio, normalmente concorda com esta visão do "problema". Ele acredita que pode ser - ou, pelo menos, deveria ser - o "capitão da sua alma". ${ }^{2}$ Mas é um clichê do alcoolismo que, depois "do primeiro gole", a motivação para parar de beber é zero. Tipicamente, a questão é colocada abertamente como uma batalha entre o "self" e o "João Canabrava". O alcoólatra pode estar planejando, ainda que secretamente, estocar suprimento para a próxima bebedeira, mas é quase impossível (no ambiente hospitalar) ver o alcoólatra sóbrio planejar sua próxima bebedeira de forma explícita. Ele não pode, aparentemente, ser o "capitão" da sua alma e desejar ou comandar abertamente sua própria bebedeira. O "capitão" pode comandar apenas sobriedade - e então não ser obedecido.

Bill W., cofundador de Alcoólicos Anônimos e ele mesmo alcoólatra, problematizou toda essa mitologia do conflito no primeiro dos famosos "Doze Passos" de AAs. O primeiro passo requer que o alcoólatra concorde que ele é impotente perante o álcool. Esse passo é normalmente entendido como uma "rendição", e muitos alcoólatras ou não são capazes de alcançá-lo, ou o alcançam apenas durante um breve período de remorso depois de uma bebedeira. AAs consideram esses casos como pouco promissores: eles ainda não chegaram no "fundo do poço"; seu desespero é inadequado, e depois de um tempo mais ou menos curto de sobriedade eles irão novamente tentar empregar o "autocontrole" para lutar contra a "tentação". Eles não irão aceitar, ou não podem aceitar, a premissa de que, embriagado ou sóbrio, toda a personalidade de um alcoólatra é uma personalidade alcoólica incapaz de lutar contra o alcoolismo. Como diz um dos folhetos de AA, "tentar usar a força de vontade é como tentar se levantar puxando os cordões dos sapatos".

Os primeiros dois passos do AA são os seguintes:

1) Admitimos nossa impotência perante o álcool e que perdemos o domínio das nossas vidas. 
2) Passamos a acreditar que um Poder superior a nós pode nos devolver a sanidade. [AA, 1939]

Na combinação desses dois passos, está implícita uma extraordinária - e, creio eu, correta - ideia: de que a experiência da derrota não apenas serve para convencer o alcoólatra de que a mudança é necessária; é ela mesma o primeiro passo para a mudança. Ser derrotado pela garrafa e saber disso é a primeira "experiência espiritual". O mito do autocontrole é, assim, desfeito por meio da demonstração de um poder superior.

Argumento, em suma, que a "sobriedade" do alcoólatra é uma variação particularmente desastrosa do dualismo cartesiano: a divisão entre Mente e Matéria, ou, nesse caso, entre a vontade consciente, ou self, e o restante da personalidade. O golpe de gênio de Bill W. foi, com o primeiro "passo", romper a estruturação desse dualismo.

Do ponto de vista filosófico, esse primeiro passo não é uma rendição. Trata-se simplesmente de uma mudança de epistemologia, do modo como o sujeito conhece sua personalidade-no-mundo. E, notavelmente, a mudança é de uma epistemologia incorreta para outra que é mais correta.

\section{Epistemologia e Ontologia}

Filósofos têm reconhecido e distinguido dois tipos de problema. Primeiro, há problema relativos a como as coisas são, o que é uma pessoa, que tipo de mundo é este. São problemas da ontologia. Segundo, há problemas relativos a como nós podemos conhecer alguma coisa, ou mais especificamente, como nós sabemos que tipo de mundo é este, e que tipo de criaturas nós somos de modo a poder conhecer alguma coisa (ou talvez nada) sobre essa questão. Esses são problemas da epistemologia. Para essas questões, tanto ontológicas quanto epistemológicas, os filósofos têm buscado encontrar respostas verdadeiras.

Mas o naturalista, ao observar o comportamento humano, fará perguntas bem diferentes. Se ele for um relativista cultural, pode concordar com os filósofos que sustentam que uma ontologia "verdadeira" é concebível, mas não perguntará se a ontologia da pessoa que ele observa é "verdadeira". Ele suporá que sua epistemologia é 
culturalmente determinada ou mesmo idiossincrática, e que a cultura como um todo faz sentido em termos da sua epistemologia e ontologia particulares.

Se, por outro lado, está claro que a epistemologia local é equivocada, então o naturalista deve estar atento à possibilidade de que a cultura como um todo nunca vá realmente fazer "sentido", ou fará sentido somente em certas circunstâncias, que o contato com outras culturas e novas tecnologias poderia corromper.

Na história natural do ser humano vivente, não é possível separar ontologia e epistemologia. Suas crenças (geralmente inconscientes) sobre que tipo de mundo é este determinarão como ele o vê e age dentro dele, e suas formas de perceber e agir determinarão suas crenças sobre a sua natureza. O homem vivente encontra-se ligado a uma rede de premissas epistemológicas e ontológicas que - independente da verdade ou falsidade dessas últimas - tornam-se parcialmente autovalidadoras para ele (Ruesch; Bateson, 1951, Cap. 8).

É estranho referir-se constantemente à epistemologia e à ontologia, e incorreto sugerir que elas sejam separáveis na história natural humana. Parece que não há uma palavra conveniente que articule os dois conceitos. As melhores aproximações seriam "estrutura cognitiva" ou "estrutura de caráter", mas esses termos não transmitem algo importante: um conjunto de premissas ou suposições habituais implícitas no relacionamento entre o homem e o ambiente, premissas estas que podem ser verdadeiras ou falsas. Neste ensaio, utilizarei o termo "epistemologia" para denotar ambos os aspectos da rede de premissas que governa a adaptação (ou má adaptação) entre humano e ambiente físico. Nos termos de George Kelly, é a partir dessas regras que um indivíduo "constrói" sua experiência.

Interesso-me em especial pelo grupo de premissas sobre as quais o conceito ocidental de self foi edificado, e, inversamente, pelas premissas que corrigem alguns dos erros ocidentais mais crassos associados àquele conceito. 


\section{A Epistemologia da Cibernética}

O que é novo e surpreendente é que nós agora temos respostas parciais para algumas dessas perguntas. No último quarto de século, houve avanços extraordinários em nosso conhecimento sobre o que é o ambiente, o que é um organismo, e, especialmente, o que é a mente. Esses avanços têm vindo da cibernética, das teorias de sistemas, teoria da informação e ciências correlatas.

Nós agora sabemos, com grau considerável de certeza, que a antiga questão sobre se a mente é imanente ou transcendente pode ser respondida em favor da imanência, e que essa resposta é uma explicação mais econômica que qualquer resposta transcendente: ela tem ao menos o suporte negativo da "Navalha de Ocam".

Do lado positivo, podemos asseverar que qualquer conjunto contínuo de eventos e objetos que conte com a complexidade de circuitos causais e relação de energia apropriadas apresentará características mentais. Ele irá comparar, ou seja, será responsivo à diferença (para além de ser afetado por "causas" físicas comuns como impacto ou força). Ele irá "processar informação" e será inevitavelmente autocorretivo - seja em direção a um ponto ótimo homeostático, seja em direção à maximização de certas variáveis.

Um "bit" de informação pode ser definido como uma diferença que faz diferença. Essa diferença, na medida em que viaja e passa por transformações sucessivas em um circuito, é uma ideia elementar.

Mas o mais relevante no presente contexto é reconhecer que nenhuma parte desse sistema internamente interativo tem controle unilateral sobre o resto, ou mesmo sobre qualquer outra parte. As características mentais são inerentes ou imanentes ao conjunto como um todo.

Esse caráter holístico é evidente mesmo em um sistema autocorretivo simples. Em um motor a vapor com um "governador", o próprio termo "governador" não é adequado se por isso entendese que este elemento do sistema possui um controle unilateral. O governador é, essencialmente, um órgão sensorial ou transdutor que opera uma transformação da diferença entre a velocidade corrente 
do motor e alguma velocidade ideal ou preferida. Esse órgão sensorial transforma essas diferenças em diferenças em alguma mensagem eferente, por exemplo, para o suprimento de combustível ou para o freio. Em outras palavras, o comportamento do governador é determinado pelo comportamento de outras partes do sistema, e indiretamente pelo seu próprio comportamento em um momento anterior.

O caráter holístico e mental do sistema é mais claramente demonstrado por esse último fato: o comportamento do governador (e, na verdade, de cada parte do circuito causal) é parcialmente determinado pelo seu próprio comportamento prévio. A mensagem material (isto é, transformações sucessivas de diferença) deve passar pelo circuito total, e o tempo necessário para que a mensagem material retorne ao lugar de onde partiu é uma característica básica do sistema como um todo. O comportamento do governador (ou de qualquer outra parte do circuito) é, portanto, em alguma medida determinado não apenas por seu passado imediato, mas pelo que ele fez em um tempo anterior ao presente durante o intervalo necessário para que a mensagem completasse o circuito. Mesmo no circuito cibernético mais simples há um tipo de memória determinativa.

A estabilidade do sistema (i.e., se ele agirá no sentido de se autocorrigir, oscilar ou disparar) depende da relação entre o produto operacional de todas as transformações de diferença ao longo de todo o circuito, e deste tempo característico. O "governador" não tem controle sobre esses fatores. Mesmo um governador humano em um sistema social encontra essas mesmas limitações. Ele é controlado pela informação que vem do sistema, e deve adaptar suas próprias ações às características temporais deste último, bem como aos efeitos de suas próprias ações passadas.

Assim, em nenhum sistema que apresenta características mentais pode uma parte ter controle unilateral sobre o todo. Em outras palavras, as características mentais do sistema são imanentes - não a alguma das partes, mas ao sistema como um todo.

A relevância dessa conclusão torna-se evidente quando perguntamos se "um computador pode pensar", ou se "a mente está no cérebro". A resposta a ambas as questões é negativa, a não ser que 
a questão se restrinja a algumas das poucas características mentais contidas no computador ou no cérebro. Um computador é autocorretivo em relação a algumas das suas variáveis internas. Ele pode, por exemplo, incluir termômetros ou outros órgãos sensoriais que são afetados pelas diferenças na temperatura funcional, e a resposta do órgão sensorial a essas diferenças pode afetar a ação de um ventilador que, em resposta, corrige a temperatura. Mas seria incorreto dizer que a operação principal do computador - transformar diferenças de entrada (input) em diferenças de saída (output) - é um "processo mental". O computador é apenas um elo em um circuito mais amplo que sempre inclui um homem e um ambiente a partir dos quais a informação é recebida, e sobre os quais as mensagens eferentes do computador têm efeito. É possível dizer que esse sistema total, ou conjunto, apresenta características mentais. Ele opera por meio de tentativa-e-erro, e tem um caráter criativo.

Da mesma forma, podemos dizer que "mente" é imanente aos circuitos cerebrais que são completos dentro do cérebro. Ou, ainda, que a mente é imanente a circuitos que são completos dentro do sistema: cérebro mais corpo. Ou, finalmente, que a mente é imanente ao sistema mais amplo - homem mais ambiente.

Em princípio, se desejamos explicar ou entender o aspecto mental de qualquer evento biológico, nós devemos levar em conta o sistema - ou seja, a rede de circuitos fechados dentro dos quais aquele evento biológico é determinado. Mas quando procuramos explicar o comportamento de um homem ou algum outro organismo, esse "sistema" normalmente não apresenta os mesmos contornos do self no sentido em que o termo é comumente (e diversamente) entendido.

Considere um homem derrubando uma árvore com um machado. Cada golpe do machado é modificado ou corrigido de acordo com a forma do corte deixado pela machadada anterior. Esse processo autocorretivo (isto é, mental) é produzido por um sistema total: árvoreolhos-cérebro-músculos-machado-machadada-árvore. É esse sistema total que tem as características de mente imanente.

Talvez o modo mais correto de colocar seja: (diferenças na árvore) - (diferenças na retina $)$ - (diferenças no cérebro) - (diferenças nos 
músculos ) - (diferenças no movimento do machado) - (diferenças na árvore), etc. O que é transmitido por meio do circuito são transformações de diferenças. E, como notado acima, uma diferença que faz diferença é uma ideia ou unidade de informação.

Mas não é assim que o ocidental médio vê a sequência do evento do corte da árvore. Ele diz "eu cortei a árvore", e acredita piamente que um agente delimitado, o "eu" (ou self), executou uma ação "intencional" delimitada sobre um objeto delimitado.

É também correto dizer que "a bola de bilhar A bateu na bola de bilhar B e a empurrou para a caçapa", e talvez também seja correto ( se pudéssemos fazê-lo) oferecer uma descrição completa e científica dos eventos que acontecem no circuito formado pelo homem e árvore. Mas o senso comum fala da mente invocando um pronome pessoal, e então chega a uma mistura de mentalismo e fisicalismo ao restringir a mente ao interior do homem e reificar a árvore. Por fim, a mente em si é reificada pela suposição de que, uma vez que o self agiu sobre o machado que agiu sobre a árvore, ele deve ser também uma "coisa". O paralelismo de sintaxe entre "eu bati na bola de bilhar" e "a bola bateu em outra bola" é totalmente enganoso.

Quando perguntamos a alguém sobre a localização e as fronteiras do "eu", essas confusões se tornam evidentes. Considere um homem cego com uma bengala. Onde começa o self do homem? Na ponta da bengala? Em seu cabo? Ou em algum outro ponto no meio da bengala? Essas questões não fazem sentido, pois a bengala é um conduto por meio do qual as diferenças são transmitidas como transformações, de modo que traçar uma linha delimitadora nesse conduto significaria cortar fora parte do circuito sistêmico que determina a locomoção do homem cego.

No mesmo sentido, órgãos sensoriais são conversores ou condutos para a informação, assim como os axônios, etc. De um ponto de vista teórico-sistêmico, é enganoso dizer que o que viaja em um axônio é um "impulso". Seria mais correto dizer que o que viaja é uma diferença, ou a transformação de uma diferença. A metáfora do "impulso" sugere uma linha de pensamento científico que se desdobra muito facilmente em balelas sobre "energia psíquica", e aqueles que falam esse tipo de coisa 
desconsideram o conteúdo informativo da quiescência. A quiescência de um axônio difere da atividade tanto quanto sua atividade difere da quiescência. Portanto, a quiescência e a atividade têm a mesma relevância informacional. A mensagem da atividade só pode ser aceita como válida se a mensagem da quiescência também puder ser confiável.

É até mesmo incorreto falar de "mensagem da atividade" e de "mensagem da quiescência". Não devemos esquecer que a informação é uma transformação da diferença, e talvez fosse melhor chamar uma mensagem de "atividade - não-quiescência" e a outra de "quiescência - não-atividade".

Considerações semelhantes se aplicam ao alcoólatra arrependido. Ele não pode simplesmente eleger a "sobriedade". Na melhor das hipóteses, ele pode apenas eleger a "sobriedade - não-embriaguez", e seu universo permanece polarizado, carregando ambas as alternativas.

A unidade total autocorretiva que processa a informação - ou, como costumo dizer, "pensa", "age" e "decide" - é um sistema cujos contornos não coincidem com as fronteiras do corpo, ou do que é popularmente chamado de self ou "consciência". É importante notar que há diferenças múltiplas entre o sistema pensante e essa compreensão senso comum do self:

1) O sistema não é uma entidade transcendente, tal como o self é normalmente entendido.

2) As ideias são imanentes a uma rede de caminhos causais ao longo dos quais as transformações da diferença são conduzidas. Em todos os casos, as "ideias" do sistema têm uma estrutura no mínimo binária. Elas não são "impulsos", mas "informação".

3) Essa rede de condutos não se limita à consciência, mas estende-se para incluir os condutos de todas as atividades mentais - autônomas e reprimidas, neurais e hormonais.

4) A rede não é limitada pela pele, mas inclui todos os condutos externos ao longo dos quais a informação pode viajar. Também inclui as diferenças efetivas que são imanentes aos "objetos" dessas informações. Inclui os caminhos de som e luz ao longo das quais trafegam as transformações das diferenças originalmente imanentes a coisas e a outras pessoas - e, especialmente, a nossas próprias ações. 
É importante notar que os princípios básicos - e, creio eu, equivocados - da epistemologia popular se reforçam mutuamente. Se, por exemplo, a premissa popular da transcendência é descartada, sua substituta imediata é uma premissa da imanência no corpo. Mas essa alternativa tampouco é aceitável, visto que boa parte da rede pensante fica fora do corpo. O assim chamado problema "corpo-mente" está posto de modo equivocado, em termos que forçam o argumento na direção de um paradoxo: se a mente é suposta como imanente ao corpo, então ela deve ser transcendente. Se transcendente, ela deve ser imanente, e assim por diante (Collingwood, 1945).

Da mesma forma, se excluímos os processos inconscientes do self e o chamamos de "ego-alienados", então esses processos tomam a coloração subjetiva das "vontades" e "forças". Essa qualidade pseudodinâmica é então estendida a um self consciente que busca "resistir" às "forças" do inconsciente. O "eu" se torna, ele mesmo, uma organização de "forças" aparentes. A ideia popular que iguala o self com a consciência conduz então à noção de que ideias são "forças"; e essa falácia é, por sua vez, sustentada pela afirmação de que o axônio carrega "impulsos". Não é fácil achar uma saída para essa bagunça.

Devemos começar examinando a estrutura da polarização alcoólica. No enunciado epistemologicamente inválido "eu lutarei contra a garrafa", quem está supostamente lutando contra o que?

\section{0 “Orgulho" do Alcoólatra}

Alcoólatras são filósofos no sentido universal de que todos os seres humanos (e todos os mamíferos) são guiados por princípios altamente abstratos dos quais não têm consciência, ou não reconhecem que o princípio que governa sua percepção e ação é filosófico. Um nome comum, embora inadequado, para tais princípios é "sentimentos" (Bateson, 1963).

Essa terminologia equivocada vem da tendência epistemológica anglo-saxônica de reificar ou atribuir ao corpo todos os fenômenos mentais que sejam periféricos à consciência. Ela é, sem dúvida, sustentada pelo fato de que o exercício e/ou frustração desses princípios são frequentemente acompanhados por sensações viscerais e outras 
sensações físicas. Creio, no entanto, que Pascal estava correto quando disse que "o coração tem razões que a própria razão desconhece".

Mas o leitor não deve esperar que o alcoólatra apresente uma imagem consistente. Quando a epistemologia subjacente é cheia de erros, suas derivações serão, inevitavelmente, ou autocontraditórias ou de escopo extremamente restrito. Um corpo coerente de teoremas não pode derivar de um corpo inconsistente de axiomas. Nesses casos, a tentativa de ser consistente leva ou à proliferação de complexidade característica da teoria psicanalítica e da teologia cristã, ou à visão extremamente limitada característica do behaviorismo contemporâneo.

Prosseguirei com meu exame do "orgulho" característico dos alcoólatras mostrando que esse princípio comportamental emana da estranha epistemologia dualística característica da civilização ocidental.

Um modo conveniente de descrever princípios como "orgulho", "dependência" ou "fatalismo" é examiná-los como resultado de um deuteroaprendizado33 (Bateson, 1942) e perguntar que contextos de aprendizado poderiam inculcar tais princípios.

1) Está claro que o princípio da vida alcoólatra que AA chama de "orgulho" não é estruturado contextualmente por sucessos passados. Eles não usam a palavra para significar orgulho por algum feito. A ênfase não é em "eu consegui", mas antes em "eu consigo..." É uma aceitação obsessiva de um desafio, um repúdio à proposição "eu não consigo".

2) Depois que o alcoólatra começou a sofrer - ou ser acusado - de alcoolismo, o princípio do "orgulho" é mobilizado por meio da proposição "eu consigo permanecer sóbrio". Porém, ser bemsucedido acaba com o "desafio". O alcoólatra fica "confiante", como dizem nos AAs. Ele relaxa a guarda, arrisca um gole, e logo já está de porre novamente. Podemos dizer que a estrutura contextual da sobriedade muda a partir daí. A sobriedade, neste ponto, deixa de ser um contexto apropriado para o "orgulho". É o risco do primeiro gole que se torna desafiador, e evoca o fatal "eu consigo $[\ldots]$ ".

3) AAs insistem que essa mudança na estrutura contextual nunca deve ocorrer. Eles reestruturam todo o contexto ao lembrar 
regularmente que "uma vez alcoólatra, sempre alcoólatra". Eles tentam fazer o alcoólatra colocar o alcoolismo dentro de si, assim como um analista jungiano busca fazer com que seu paciente, ao descobrir seu "tipo psicológico", aprenda a viver com as forças e fraquezas daquele tipo. Em contraste, a estrutura contextual do "orgulho" do alcoólatra exclui o alcoolismo do self: "Eu consigo resistir à bebida".

4) O componente desafiador do "orgulho" do alcoólatra envolve correr riscos. O princípio pode assumir a seguinte forma: "eu consigo fazer algo onde o sucesso é improvável e o fracasso, desastroso". Claramente, esse princípio nunca servirá para manter a sobriedade. Assim que o sucesso começa a parecer provável, o alcoólatra deve desafiar o risco de uma dose. O elemento de "azar" ou "probabilidade" de fracasso joga o desafio para além dos limites do self. "Se o fracasso ocorre, ele não é meu". O "orgulho" do alcoólatra estreita progressivamente o conceito de self, colocando o que acontece fora do seu escopo.

5) O princípio do orgulho-em-arriscar é, finalmente, quase suicida. Tudo bem testar uma vez se o universo está do nosso lado, mas fazer isso várias vezes seguidas, com um rigor da prova cada vez maior, é se lançar num projeto que só provará que o universo o odeia. Não obstante, as narrativas dos AAs mostram repetidamente que, no auge do desespero, o orgulho às vezes impede o suicídio. O repouso final não deve ser trazido pelo self (Bill's Story, AA, 1939).

\section{Orgulho e Simetria}

O chamado orgulho do alcoólatra sempre presume um "outro" real ou fictício; sua definição contextual completa exige, portanto, que caracterizemos a relação real ou imaginária com esse "outro". O primeiro passo é classificá-la como "simétrica" ou "complementar" (Bateson, 1936). Fazê-lo não é tão simples quando este "outro" é uma criação do inconsciente, mas veremos que as indicações para essa classificação são claras. 
Uma digressão explanatória faz-se, todavia, necessária. O primeiro critério é simples:

Se, em uma relação binária, os comportamentos de A e B são considerados (por A e B) como similares e ligados de tal forma que mais de um determinado comportamento por parte de A estimula mais do mesmo comportamento por parte de B e vice-versa, então a relação entre esses comportamentos é "simétrica".

Se, por outro lado, os comportamentos de A e B são dissimilares, porém mutuamente ajustados (como, por exemplo, o voyeurismo se ajusta ao exibicionismo), e os comportamentos se ligam de tal forma que mais de um determinado comportamento por parte de A estimula mais do comportamento ajustado por parte de B, então a relação entre esses comportamentos é "complementar".

Exemplos comuns de relações simétricas simples são corridas armamentistas, imitar os vizinhos, emulação atlética ou lutas de boxe. Exemplos comuns de relações complementares incluem dominaçãosubmissão, sadomasoquismo, cuidado-dependência ou voyeurismoexibicionismo.

Considerações mais complexas emergem quando tipos lógicos superiores se fazem presentes. Por exemplo: A e B podem competir na oferta de dádivas, sobrepondo assim uma moldura simétrica mais ampla a comportamentos complementares primários. Ou, contrariamente, um terapeuta pode engajar-se competitivamente com um paciente em alguma forma de jogo terapêutico, estabelecendo uma moldura de cuidado complementar em torno das transações simétricas primárias do jogo.

Vários tipos de "duplo vínculo" são produzidos quando A e B percebem as premissas da sua relação em termos diferentes - A por considerar o comportamento de B como competitivo quando B pensa que está ajudando A, e assim por diante.

Aqui não nos preocupamos com essas complexidades, pois o "outro" imaginário ou sua contraparte no caso do "orgulho" do alcoólatra não joga, creio eu, os jogos complexos que são característicos das "vozes" do esquizofrênico. 
Ambas as relações, complementares e simétricas, são suscetíveis de transformações progressivas do tipo que eu chamei de cismogênese (Bateson, 1936). Disputas simétricas e corridas armamentistas podem, como se diz, "escalar"; e o padrão normal de cuidado-dependência entre pais e filhos pode se tornar doentio. Esses desenvolvimentos potencialmente patológicos se devem a retroalimentações positivas que não encontram controle ou correção dentro do sistema, e podem - como colocado - ocorrer em sistemas tanto complementares quanto simétricos. Em sistemas mistos, no entanto, a cismogênese é necessariamente reduzida. Uma corrida armamentista entre duas nações será reduzida pela aceitação de relações complementares entre elas como dominação, dependência, admiração, e assim por diante. Ela se intensifica quando esses temas são repudiados.

Sem dúvida, essa relação antitética entre temas complementares e simétricos se deve ao fato de que um é o oposto lógico do outro. Em uma corrida armamentista simétrica simples, a nação A é motivada a maiores esforços pela sua estimativa da maior força de B. Quando ela estima que B é mais fraca, a nação A relaxará seus esforços. Mas o oposto exato irá acontecer caso a estruturação da relação por parte de A seja complementar. Observando que B é mais fraca que ela, A seguirá em frente com suas esperanças de conquista (Bateson, 1946; Richardson, 1935).

Essa antítese entre padrões complementares e simétricos pode ser mais que simplesmente lógica. Notavelmente, na teoria psicanalítica (Erikson, 1937), os padrões chamados "libidinosos" e que são modalidades das zonas erógenas são todos complementares. Intrusão, inclusão, exclusão, recepção, retenção - todos são classificados como "libidinosos". Já a rivalidade, competição e afins se enquadram na rubrica do "ego" e "defesa".

Também é possível que os dois códigos antitéticos - simétrico e complementar - possam ser fisiologicamente representados por estados contrastantes do sistema nervoso central. As transformações progressivas da cimogênese podem alcançar um clímax ou inversões repentinas. Ódio simétrico pode de repente se transformar em luto; o animal que se retira com o rabo entre as pernas pode abruptamente 
voltar-se contra seu oponente em uma desesperada batalha simétrica até a morte. O valentão pode subitamente tornar-se um covarde quando é desafiado, e o lobo derrotado em um conflito simétrico pode repentinamente dar sinais de "rendição" para evitar ataques ulteriores.

Este último exemplo é especialmente interessante. Se a luta entre os lobos é simétrica - ou seja, se o lobo A é estimulado a um comportamento mais agressivo pelo comportamento agressivo do lobo B - então se B repentinamente exibe o que podemos chamar de "agressão negativa", A não será capaz de continuar lutando a menos que possa mudar rapidamente para um estado mental complementar no qual a fraqueza de B seja um estímulo para sua agressão. Nos termos da hipótese de modos simétricos e complementares, torna-se desnecessário postular um efeito "inibitório" específico para o sinal de rendição.

Seres humanos, que possuem linguagem, podem aplicar o rótulo "agressão" a qualquer tentativa de causar dano ao outro, independentemente de a tentativa ser estimulada pela fraqueza ou força deste último. Mas no nível pré-linguístico dos mamíferos, esses dois tipos de "agressão" devem parecer totalmente diferentes. Dizem que do ponto de vista do leão, um "ataque" a uma zebra é totalmente diferente de um "ataque" a outro leão (Lorenz, 1966).

Já disse o suficiente para que possa agora colocar a seguinte questão: O orgulho do alcoólatra é contextualmente estruturado de forma simétrica ou complementar?

Em primeiro lugar, há uma forte tendência para a simetria nos hábitos quotidianos da cultura ocidental. Completamente à parte do alcoolismo aditivo, dois homens bebendo juntos são impelidos pela convenção de que um deve igualar o outro, copo a copo. Nesse estágio, o "outro" ainda é real, e a simetria ou rivalidade entre eles é amigável.

À medida que o alcoólatra se torna adicto e tenta resistir à bebida, ele começa a descobrir que é difícil resistir ao contexto social no qual ele deve se igualar a seus amigos no ato de beber. AAs dizem: "Deus sabe que tentamos duramente e por muito tempo beber como as outras pessoas!". 
À medida que as coisas vão piorando, o alcoólatra tende a se tornar um bebedor solitário, e a exibir um amplo espectro de respostas ao desafio. Sua esposa e amigos começam a sugerir que beber é uma fraqueza, e ele pode responder, simetricamente, ressentindo-se deles ou reafirmando sua capacidade de resistir à bebida. Todavia, como é característico das respostas simétricas, um breve momento de luta bem sucedida enfraquece sua força de vontade e ele logo volta a beber. Esforços simétricos requerem oposição contínua por parte do oponente.

Gradualmente, o foco da batalha muda, e o alcoólatra se vê envolvido em um tipo novo e ainda mais fatal de conflito simétrico. Ele agora deve provar que a bebida não irá matá-lo. Sua "cabeça está sangrando, mas não está curvada". Ele ainda é o "capitão da sua alma" - seja lá o que isso signifique.

Enquanto isso, seu relacionamento com a esposa, o patrão e os amigos foi deteriorando. Ele nunca apreciou o status complementar de seu chefe como uma autoridade; e à medida que sua situação vai piorando, a esposa é levada cada vez mais a assumir um papel complementar. Ela pode tentar exercer autoridade, ou se torna protetora, ou demonstra paciência, mas tudo isso só provoca raiva ou vergonha. Seu "orgulho" simétrico não pode tolerar um papel complementar.

Em suma, a relação entre o alcoólatra e seu "outro" fictício ou real é claramente simétrico e cismogênico. Ela escala. Veremos que a conversão religiosa do alcoólatra salvo pelos AAs pode ser descrita como uma mudança dramática desse hábito, ou epistemologia simétrica, para uma visão quase puramente complementar do seu relacionamento com os outros, com o universo e com Deus.

\section{Orgulho ou Prova Invertida?}

Alcoólatras podem parecer teimosos, mas não são estúpidos. A porção da sua mente onde sua política é decidida é profunda demais para que a palavra "estupidez" possa ser aplicada. Esses níveis da mente são pré-linguísticos, e a computação que acontece ali é codificada num processo primário. 
Tanto nos sonhos quanto nas interações entre mamíferos, o único meio de avançar uma proposição que contenha sua própria negação ("eu não vou morder você" ou "eu não estou com medo dele") é por meio de uma imaginação elaborada ou a atuação da proposição a ser negada, conduzindo a um reductio ad absurdum. "Eu não vou mordê-lo" é alcançado entre dois mamíferos por meio de um combate experimental que é um "não-combate", por vezes chamado "jogo". É por isso que o comportamento "agonístico" frequentemente evolui para um cumprimento amistoso (Bateson, 1969).

Nesse sentido, o assim chamado orgulho do alcoólatra é, em alguma medida, irônico. É um esforço determinado de testar algo como um "autocontrole" com um propósito ulterior, mas não enunciável, de provar que "autocontrole" é ineficaz e absurdo: "Isso simplesmente não funciona”. Essa proposição última, por conter uma negação simples, não deve ser expressa no processo primário. Sua expressão final é em uma ação - tomar um drinque. A heroica batalha contra a garrafa, aquele "outro" fictício, termina em um "beijo entre amigos".

A favor dessa hipótese, há o fato inegável de que o teste do autocontrole leva de volta à bebida. E, como argumentei acima, a epistemologia do autocontrole que os amigos impõem ao alcoólatra é monstruosa. Se este é o caso, então o alcoólatra está correto em rejeitála. Ele chegou à reductio ad absurdum da epistemologia convencional.

Mas essa descrição do alcance do reductio ad absurdum se aproxima da teleologia. ${ }^{4}$ Se a proposição "isso não vai funcionar" não puder ser mantida dentro da codificação do processo primário, como a computação do processo primário poderá direcionar o organismo a tentar aqueles cursos de ação que demonstrarão que "isso não vai funcionar?".

Problemas desse tipo são frequentes na psiquiatria, e talvez só possam ser resolvidos por um modelo no qual, em certas circunstancias, o desconforto do organismo ativa um feedback loop (alça de retroalimentação) positivo que aumenta o comportamento que precede o desconforto. Essa retroalimentação positiva confirmará que era realmente aquele comportamento particular que trazia o desconforto, e pode elevar o desconforto para um nível em que a mudança se torne possível. 
Na psicoterapia, essa retroalimentação positiva é comumente gerada pelo terapeuta ao empurrar o paciente na direção de seus sintomas - uma técnica que tem sido chamada de "duplo vínculo terapêutico". Um exemplo dessa técnica é mencionado abaixo, quando um membro de AA desafia o alcoólatra a "beber controladamente" para que ele descubra por si próprio que não possui esse controle.

Além disso, é comum que os sintomas e alucinações do esquizofrênico - como os sonhos - constituam uma experiência corretiva, de forma que todo o episódio esquizofrênico assuma o caráter de uma autoiniciação. A descrição de Barbara O’Brien da sua própria psicose talvez seja o exemplo mais contundente desse fenômeno, que foi discutido noutro lugar (Bateson, 1961).

A possível existência desse feedback loop positivo, que irá causar uma perda de controle na direção de um aumento do desconforto até algum limite (que pode estar do outro lado da morte), não está incluída nas teorias convencionais da aprendizagem. Mas uma tendência a verificar o desagradável buscando a repetição constante dessa experiência é um traço humano comum. Talvez seja aquilo que Freud chamou de "pulsão de morte".

\section{O Estado de Embriaguez}

O que foi dito acima sobre o orgulho simétrico é apenas parte do quadro: o estado de mente do alcoólatra lutando contra a garrafa. Esse estado é claramente desagradável, e pouco realista. Seus "outros" são totalmente imaginários, ou distorções grosseiras das pessoas que ele ama ou das quais depende. Ele tem uma alternativa a esse estado desagradável: pode embriagar-se. Ou, "pelo menos", tomar um drinque.

Com essa entrega complementar, que o alcoólatra frequentemente vê como um ato de ressentimento - um "golpe de despedida" em uma guerra simétrica -, toda sua epistemologia muda. Suas ansiedades, ressentimentos e pânico desaparecem como num passe de mágica. Seu autocontrole é relaxado, mas sua necessidade de comparar-se com outros diminui ainda mais. Ele sente o calor fisiológico do álcool em suas veias e, em muitos casos, um aquecimento psicológico correspondente em 
relação aos outros. Ele pode estar eufórico ou raivoso, mas ao menos se tornou novamente parte da cena humana.

Dados baseados na tese de que a passagem da sobriedade para a intoxicação é também uma passagem do desafio simétrico para a complementaridade são escassos, e sempre confundidos pelas distorções da memória e pela complexa toxicidade do álcool. Mas há fortes evidências na música e na história de que se trata de uma passagem desse tipo. Em rituais, compartilhar o vinho sempre representou a agregação social de pessoas unidas em "comunhão" religiosa ou Gemütlichkeit seculares. Em um sentido bastante literal, o álcool supostamente faz com que o indivíduo se veja, e aja, como parte de um grupo. Ou seja, ele habilita a complementaridade nas relações que o cercam.

\section{No Fundo do Poço}

AAs dão grande importância a esse fenômeno e consideram o alcoólatra que ainda não atingiu o fundo do poço um candidato ruim para sua ajuda. Eles tendem a explicar o fracasso afirmando que o indivíduo que recai no alcoolismo ainda não chegou no "fundo do poço".

Decerto, muitas tragédias podem fazer com que um alcoólatra chegue ao fundo do poço. Acidentes, um ataque de delirium tremens, um período de tempo alcoolizado do qual não guarda recordação, rejeição por parte da esposa, demissão do trabalho, diagnóstico de caso perdido, e assim por diante - qualquer um pode ter este efeito. AAs afirmam que o "fundo do poço" é diferente para diferentes pessoas, e alguns podem morrer antes de chegar lá. ${ }^{5}$

É possível ainda que o "fundo" seja alcançado diversas vezes pela mesma pessoa; que o "fundo" seja um surto de pânico que oferece um momento favorável para mudanças, mas não um momento onde a mudança seja inevitável. Amigos, parentes e mesmo terapeutas podem remover o alcoólatra do seu pânico, por meio de drogas ou tranquilização, e fazer com que ele "se recupere" e volte ao seu "orgulho" e ao alcoolismo - somente para chegar a um "fundo do poço" ainda mais desastroso tempos depois, quando passa a estar novamente pronto para a mudança. As tentativas de mudar um alcoólatra, fora 
desses momentos de pânico, estão provavelmente fadadas ao fracasso. A natureza do pânico é esclarecida pela seguinte descrição de um "teste":

Não gostamos de definir nenhum indivíduo como alcoólatra, mas você mesmo pode se autodiagnosticar. Entre no bar mais próximo e tente beber moderadamente. Tente começar a beber e parar de repente. Tente mais de uma vez. Não levará muito tempo para você decidir, se for honesto consigo mesmo. Uma ressaca grave pode ser valiosa se com isso você conseguir um melhor conhecimento da sua condição. (AA, 1939, p. 431)

Podemos comparar esse teste a um motorista que freia abruptamente numa pista escorregadia: ele rapidamente descobrirá que seu controle é limitado. (A metáfora em inglês "linha de derrapagem" para o bairro dos alcoólatras na cidade não é de todo despropositada.)

O pânico do alcoólatra que atinge o fundo do poço é o pânico de um homem que pensava ter controle sobre seu veículo, mas de repente descobre que é o veículo que corre com ele. Repentinamente, a pressão feita sobre aquilo que ele conhece como freio parece fazer o veículo acelerar. É o pânico de descobrir que isto (o sistema, ou seja, o motorista mais o veículo) é maior do que ele.

Nos termos propostos aqui, podemos dizer que chegar ao fundo do poço exemplifica a teoria de sistemas em três níveis:

1) O alcoólatra trabalha no desconforto da sobriedade até um limiar em que ele destrói a epistemologia do "autocontrole". Ele fica, então, embriagado - porque o sistema é maior que ele -, e o melhor é se render.

2) Ele trabalha repetidamente para se embriagar até provar que há um sistema ainda maior. Ele chega então ao pânico do "fundo do poço".

3) Se amigos e terapeutas o tranquilizam, ele pode chegar a um ajustamento mais instável - tornando-se adicto à ajuda deles - até que demonstre que esse sistema não funcionará, e atinja o "fundo do poço" novamente, mas num nível ainda mais baixo. Neste, como em todos os sistemas cibernéticos, 
o sinal (positivo ou negativo) do efeito de qualquer intrusão sobre o sistema depende do timing.

4) Finalmente, o fenômeno de chegar ao "fundo do poço" se relaciona de modo complexo com a experiência do duplo vínculo (Bateson et al., 1956). Bill W. conta que atingiu seu fundo do poço quando foi diagnosticado como alcoólatra sem perspectiva de cura pelo Dr. Willian D. Silkwork em 1939 - este evento é considerado o início da história do AA (AA, 1957, p. vii). O Dr. Silkwork também

[...] nos ofereceu as ferramentas capazes de furar o mais duro ego alcoólatra, aquelas frases demolidoras com que ele descreveu nossa doença: a obsessão da mente que nos compele a beber e a alergia do corpo que nos condena a enlouquecer ou morrer. (Bill W. em AA, 1957, p. 13, grifo no original)

Este é o duplo vínculo corretamente fundado na epistemologia dicotômica do alcoólatra que opõe mente a corpo. Ele é forçado por essas palavras a recuar, até o ponto em que somente uma mudança involuntária na epistemologia inconsciente mais profunda - uma experiência espiritual - poderá tornar irrelevante aquela descrição letal.

\section{A Teologia de Alcoólicos Anônimos}

Alguns dos pontos notáveis da teologia de AA são:

1) Há um Poder maior que o self. A cibernética vai um pouco além e reconhece que o que entendemos como "eu" é apenas uma pequena parte de um sistema muito mais amplo de tentativa-e-erro que executa o pensamento, a ação e a decisão. Esse sistema inclui todos os circuitos informacionais relevantes para uma decisão num determinado momento. O self é uma falsa reificação de uma parte inadequadamente delimitada desse campo mais amplo de processos interconectados. A cibernética também reconhece que duas ou mais pessoas - qualquer grupo de pessoas - podem, juntas, formar tal sistema de pensamento e ação. 
2) Esse Poder é sentido de modo pessoal, e intimamente ligado a cada pessoa. É "Deus como você o concebe". Ciberneticamente falando, "minha" relação com qualquer sistema mais amplo à minha volta, incluindo outras coisas e pessoas, será diferente da "sua" relação com algum sistema semelhante no seu entorno. A relação "parte de" deve necessariamente e logicamente ser sempre complementar, mas o sentido da frase "parte de" será diferente para cada pessoa. ${ }^{6}$ Essa diferença é especialmente importante em sistemas que contêm mais de uma pessoa. $\mathrm{O}$ sistema ou "poder" deve necessariamente parecer diferente dependendo de onde cada pessoa está. Além disso, espera-se que tais sistemas, quando se encontram, reconheçam um ao outro como sistemas nesse sentido. A "beleza" da floresta pela qual eu ando é meu reconhecimento tanto das árvores individuais como da ecologia total das florestas como sistemas. Um reconhecimento estético desse tipo é ainda mais evidente quando eu falo com outra pessoa.

3) Um relacionamento favorável com esse Poder é descoberto quando a pessoa chega ao "fundo do poço" e "se rende".

4) Para os homens e especialmente os alcoólatras, resistir a esse Poder pode ser desastroso. A filosofia materialista que coloca o "homem" contra seu ambiente está desmoronando rapidamente, à medida que o homem tecnológico vai se tornando cada vez mais capaz de se opor a sistemas mais amplos. Cada batalha que ele vence traz uma ameaça de desastre. A unidade de sobrevivência - na ética como na evolução - não é o organismo ou a espécie, mas o sistema mais amplo ou "poder" dentro do qual a criatura vive. Se a criatura destrói seu ambiente, ela destrói a si mesma.

5) Mas - e isso é importante - o Poder não recompensa nem pune. Ele não tem "poder" nesse sentido. Na frase bíblica, "todas as coisas cooperam para o bem daqueles que conhecem a Deus"; e contrariamente, para aqueles que não o conhecem. A ideia de um poder no sentido de um controle unilateral é estranha ao AA. Sua organização é estritamente "democrática" (nos seus 
termos), e mesmo sua divindade se liga àquilo que podemos chamar de um determinismo sistêmico. A mesma limitação se aplica tanto à relação entre o padrinho de AA e o bêbado que ele pretende ajudar, como à relação entre o escritório central de AA e cada grupo local.

6) Tomados juntos, os dois primeiros passos de Alcoólicos Anônimos identificam a adição como uma manifestação desse Poder.

7) A relação saudável entre cada pessoa e esse Poder é complementar - o oposto do "orgulho" do alcoólatra, que se baseia numa relação simétrica com um "outro" imaginado. A cismogênese é sempre mais poderosa que seus participantes.

8) A qualidade e o conteúdo da relação de cada pessoa com o Poder estão indicados ou refletidos na estrutura social de AA. O aspecto secular desse sistema - sua governança - se encontra delineado nas "Doze Tradições" (AA, 1957), que suplementam os "Doze Passos" - estes últimos tratando da relação do homem com o Poder. Os dois documentos se sobrepõem no Décimo-Segundo Passo, que estabelece a ajuda a outros alcoólatras como exercício espiritual necessário sem o qual o membro fica vulnerável a uma recaída. O sistema como um todo é uma religião durkheimiana, no sentido de que a relação entre o homem e sua comunidade é paralela à relação entre homem e Deus. "AA são um Poder superior a todos nós" (AA, 1957, p. 288).

Em suma, a relação de cada indivíduo com o "Poder" é melhor definida pelos termos "faz parte de".

9) Anonimato. É preciso entender que, no pensamento e na teologia de AA, anonimato significa muito mais que a simples proteção de seus membros contra a exposição pública e a vergonha. Com a crescente fama e sucesso da organização como um todo, tornou-se tentador para seus membros utilizarem a sua filiação como recurso positivo em relacionamentos públicos, na política, educação e muitos outros campos. Bill. W., cofundador da organização, se deparou com essa tentação desde os 
primeiros dias, e discutiu a questão em um artigo publicado (AA, 1957, p. 286-294). Ele logo percebeu que qualquer busca por holofotes é um perigo pessoal e espiritual para o membro, que não deve se sujeitar a esse tipo de autopromoção. Além disso, seria fatal para a organização como um todo envolverse em política, controvérsias religiosas e reformas sociais. Ele afirma claramente que os erros do alcoólatra são os mesmos que o das "forças que hoje estão destruindo o mundo", mas AA não se propõem a salvar o mundo. Seu único propósito é "levar a mensagem de AA ao alcoólatra doente que a desejar". Ele conclui que o anonimato é "o maior símbolo de autossacrifício que conhecemos". A décima-segunda das "Doze Tradições" afirma que "o anonimato é a fundação espiritual das nossas tradições, sempre nos lembrando de colocar os princípios antes das personalidades".

A isso podemos acrescentar que o anonimato é também uma afirmação profunda da relação sistêmica entre parte e todo. Alguns teóricos de sistemas iriam ainda mais longe, pois uma grande tentação para a teoria de sistemas é reificar conceitos teóricos. Anatol Holt diz que queria um adesivo de para-choque que dissesse (um tanto paradoxalmente): “Elimine substantivos" (Fundação Wenner Gren).

10) Prece. O uso da prece por AA também afirma a complementaridade da relação parte-todo por meio da técnica bem simples de pedir por aquela relação. Eles oram por características pessoais como a humildade, que são exercidas no próprio ato de orar. Se o ato da prece for sincero (o que não é tão fácil), Deus nada pode fazer a não ser atender ao pedido. E isso é especialmente verdadeiro no caso de "Deus, como você o concebe". Essa tautologia autoconfirmatória, que contém sua própria beleza, é precisamente o bálsamo necessário depois dos angustiantes duplos vínculos típicos do fundo do poço.

Um pouco mais complexa é a famosa "Oração da Serenidade": "Concedei-me, Senhor, a serenidade para aceitar as coisas que não podemos mudar, coragem para mudar aquelas que podemos, e a sabedoria para discernir a diferença entre elas". ${ }^{7}$ 
Se os duplos vínculos causam angústia e desespero e destroem as premissas epistemológicas pessoais num nível profundo, então, inversamente, para que estas feridas se curem e uma nova epistemologia se desenvolva alguma mudança de duplo vínculo faz-se necessária. O duplo vínculo leva ao desespero: "não há alternativa". A Oração da Serenidade explicitamente liberta o adorador desses laços enlouquecedores.

A este respeito, vale mencionar que o grande esquizofrênico, John Perceval, notava uma mudança em suas "vozes". No começo da sua psicose elas o atormentavam com "ordens contraditórias" (ou, nos meus termos, duplos vínculos), mas ele começou a se recuperar quando elas passaram a lhe oferecer escolhas entre alternativas claramente definidas.

11) AAs diferem profundamente de sistemas mentais naturais como a família ou uma floresta de carvalhos em ao menos um ponto. A organização tem um único propósito - “levar a mensagem de AA ao alcoólatra doente que a desejar" -, e se dedica a maximizá-lo. Nesse quesito, AAs não são mais sofisticados que a General Motors ou uma nação ocidental. Mas sistemas biológicos, diferentes daqueles baseados em ideias ocidentais (e especialmente no dinheiro), têm propósitos múltiplos. Não há, na floresta de carvalhos, uma única variável para a qual todo o sistema se encontre orientado, e à qual todas as demais variáveis se encontrem submetidas. E, com efeito, a floresta de carvalhos funciona na direção de ótima, e não de máxima. Suas necessidades são saciáveis, e muito de qualquer coisa se torna tóxico.

Mas há o seguinte: o único propósito de AA direciona-se para o exterior, e visa uma relação não-competitiva com o mundo mais amplo. A variável a ser maximizada é uma complementaridade, e é da natureza do "serviço" e não da dominação. 


\section{O Status Epistemológico de Premissas Complementares e Simétricas}

Notei anteriormente que, na interação humana, a simetria e a complementaridade podem ser combinadas de maneiras complexas. Portanto, é razoável perguntar como é possível considerar esses temas como sendo tão fundamentais a ponto de serem chamados de "epistemológicos", mesmo em um estudo de história natural das premissas culturais e interpessoais.

A resposta parece recair sobre o que significa "fundamental" em tal estudo da história natural do homem; e o termo parece carregar dois tipos de significado.

Primeiro, eu chamo de mais fundamentais as premissas que se encontram integradas de modo mais profundo na mente, que têm "programação mais firme" e são menos suscetíveis a mudanças. O orgulho simétrico ou a autoconfiança exagerada do alcoólatra são fundamentais neste sentido.

Segundo, chamo de mais fundamentais as premissas de mente que se referem a sistemas ou formas mais amplas, e não menores, do universo. A proposição "a grama é verde" é menos fundamental que a proposição "diferenças de cor fazem uma diferença".

Contudo, se perguntamos o que acontece quando premissas são alteradas, fica claro que essas duas definições de "fundamental" se sobrepõem em larga medida. Se um homem alcança ou sofre mudanças em premissas que se encontram profundamente entranhadas na sua mente, ele certamente perceberá que os resultados dessa mudança se ramificarão pelo seu universo como um todo. Podemos chamar essas mudanças de "epistemológicas".

Resta então a questão sobre o que é epistemologicamente "correto" e epistemologicamente "errado". A mudança do "orgulho" simétrico do alcoólatra para os tipos de complementaridades de AA é uma correção da sua epistemologia? E a complementaridade é sempre de uma forma melhor que a simetria?

Para o membro de AA, pode ser verdadeiro que a complementaridade seja sempre preferível à simetria, e que mesmo a rivalidade trivial de um jogo de tênis ou xadrez possa ser perigosa. Um episódio superficial 
pode tocar uma premissa simétrica profundamente entranhada. Mas isso não significa que o tênis ou o xadrez proponha erro epistemológico para todos.

O problema ético e filosófico diz respeito apenas aos níveis mais amplos do universo, ou mais profundos da psicologia. Se acreditamos profunda e inconscientemente que nossas relações com o sistema mais amplo que nos envolve - o "Poder maior que nós mesmos" - são simétricas e emulativas, então estamos equivocados.

\section{Limitações da Hipótese}

Finalmente, a presente proposta analítica está sujeita às seguintes limitações e implicações:

1) Não afirmo que todos os alcoólatras operam de acordo com a lógica delineada aqui. É bem possível que existam outros tipos de alcoólatras, e é quase certo de que a adição alcoólica em outras culturas siga outras linhas.

2) Não afirmo que o modo de Alcoólicos Anônimos seja a única forma de viver corretamente, ou que sua teologia seja a única derivação correta da epistemologia da cibernética e da teoria de sistemas.

3) Não afirmo que todas as transações entre seres humanos devam ser complementares, embora esteja claro que a relação entre o indivíduo e o sistema mais amplo do qual ele faz parte deva ser necessariamente assim. Relações entre pessoas serão (espero) sempre complexas.

4) Afirmo, no entanto, que o mundo não alcoólico tem muitas lições a aprender com a epistemologia da teoria de sistemas e do modo de operação de AA. Se continuarmos operando nos termos de um dualismo cartesiano que opõe mente à matéria, provavelmente iremos continuar a ver o mundo em termos que opõem Deus ao homem; elite ao povo; raça eleita aos demais; nações a nações; e homem ao ambiente. É improvável que uma espécie que possui tanto uma tecnologia avançada quanto essa forma estranha de ver seu mundo possa persistir. 


\section{Notas}

1 Texto originalmente publicado em Psychiatry, v. 34, n. 1, p. 1-18, 1971.

2 Essa expressão é utilizada por AA para ironizar o alcoólatra que tenta usar a força de vontade contra a bebida. A citação, junto com a frase "minha cabeça está sangrando, mas não está curvada", vem do poema Invictus de William Ernest Henley - um deficiente físico, mas não alcoólatra. O emprego da vontade para conquistar a dor e a deficiência física provavelmente não é comparável ao uso da vontade por parte do alcoólatra.

3 Esse uso da estrutura contextual formal como mecanismo descritivo não presume necessariamente que o princípio discutido seja total ou parcialmente de fato aprendido em contextos com uma estrutura formal apropriada. O princípio pode ter sido geneticamente determinado, e ainda assim ser melhor descrito pela delineação formal dos contextos nos quais ele é exemplificado. É precisamente esse ajuste do comportamento ao contexto que dificulta ou impossibilita determinar se um princípio de comportamento era geneticamente determinado ou foi aprendido naquele contexto. Ver Bateson (1942).

4 Estudo da finalidade. Doutrina que considera o mundo como um sistema de relações entre meios e fins; teologismo. [nesta acepção, finalismo]. Estudo dos fins humanos.

5 Comunicação pessoal de um membro.

6 Essa diversidade de estilos de integração pode explicar o fato de algumas pessoas se tornarem alcoólatras e outras não.

7 Este não é um documento original de AA, e sua autoria é desconhecida. Ocorrem pequenas variações no texto. Citei a forma que prefiro pessoalmente (AA, 1957, p. 196).

\section{Referências}

AA - [ALCOHOLICS ANONYMOUS]. Alcoholics Anonymous. New York: Works Publishing, 1939.

AA - [ALCOHOLICS ANONYMOUS]. Alcoholics Anonymous Comes of Age. Harper: [s.n], 1957.

BATESON, Gregory. Naven. Cambridge: Cambridge Univ. Press, 1936.

BATESON, Gregory. Social Planning and the Concept of 'Deutero-learning. In: CONFERENCE ON SCIENCE, PHILOSOPHY, AND RELIGION, SECOND SYMPOSIUM. Anais [...]. Harper, 1942.

BATESON, Gregory. The Pattern of an Armaments Race-Part I: An Anthropological Approach, Bull. Atomic Scientists, [S.l.], v. 2, n. 5, p. 10-11, 1946.

BATESON, Gregory et al. Toward a Theory of Schizophrenia. Behuviural Science, [S.l.], v. 1, p. 251-264, 1956.

BATESON, Gregory (ed.). Perceval's Narrative. Stanford: Stanford Univ. Press, 1961. 
BATESON, Gregory. A Social Scientist Views the Emotions. In: KNAPP, P. (ed.). Expression of the Emotions in Man. Madison: International Univ. Press, 1963.

BATESON, Gregory. Metalogue: What Is an Instinct? In: SEBEOK, T. (ed.). Approaches to Animal Communication. The Hague: Mouton, 1969. COLLINGWOOD, Robin George. The Idea of Nature. Oxford: Oxford Univ. Press, 1945.

ERIKSON, Erik H. Configurations in Play-Clinical Notes. Psychoanal. @rt., [S.l.], v. 6, p. 139-214, 1937.

LORENZ, Konrad. On Awession. Harcourt: Brace \& World, 1966.

O'BRIEN, Barbara. Operators and Things: The Inner Life of a Schizophrenic. Cambridge: Mass., Arlington Books, 1958.

RICHARDSON, Lewis Fry. Generalized Foreign Politics. British J. Psychology, Monogr, Supplements, 1939.

RUESCH, Jurgen; BATESON, Gregory. Communication: the Social Matrix of Psychiatry. Norton: [s.n.], 1951.

WENNER-GREN FOUNDATION. Conference on the effects of conscious purpose on human adaptation. Knopf, 1968. [no prelo].

Recebido em 04/07/2019

Aceito em 19/07/2019

\section{Gregory Bateson (9 de maio de 1904 - 4 de julho de 1980)}

Foi um antropólogo inglês, linguista, semiólogo e ciberneticista, cujo trabalho cruzava o de muitos outros campos. Na década de 1940, ele ajudou a estender a teoria de sistemas e a cibernética para as ciências sociais e comportamentais. Seus escritos incluem sua monografia clássica a partir de seu trabalho de campo entre os Iatmul "Naven" (1936), além de "Balinese Character" (1942), "Passos para uma ecologia da mente" (1972) e "Mente e natureza" (1979).

\section{Letícia Maria Costa da N. Cesarino}

Doutora em Antropologia Social, Professora da UFSC

E-mail: letícia.cesarino@gmail.com 